supplementary material for

\title{
Determination of Cyanide in Water and Food Samples Using an Efficient Naphthalene-Based Ratiometric Fluorescent Probe
}

Lingliang Long, ${ }^{\mathrm{a}, *}$ Xiangqi Yuan, ${ }^{\mathrm{a}}$ Siyu Cao, ${ }^{\mathrm{a}}$ Yuanyuan Han, ${ }^{\mathrm{a}}$ Weiguo Liu, ${ }^{\mathrm{a}}$ Qian Chen, ${ }^{a}$ Zhixiang Han, ${ }^{\mathrm{b}}$ Kun Wang, ${ }^{\mathrm{a}, \mathrm{c} *}$

a School of Chemistry and Chemical Engineering, Jiangsu University, Zhenjiang, Jiangsu 212013 (P. R. China).

$\mathrm{b}$ School of the Environment and Safety Engineering, Jiangsu University, Zhenjiang, Jiangsu 212013 (P. R. China).

c Key Laboratory of Optic-electric Sensing and Analytical Chemistry for Life Science, Ministry of Education, College of Chemistry and Molecular Engineering, Qingdao University of Science and Technology, Qingdao, Shandong 266042 (P. R. China).

Email: longlingliang@163.com; wangkun@ujs.edu.cn. 


\section{Reagents and apparatus}

The reagents used in all experiments were directly obtained from commercial suppliers. The organic solvents were dried through standard methods and then distilled before use. The water employed in the experiments were purified by distillation. Various anions or biological molecules were obtained from $\mathrm{KCN}, \mathrm{NaF}, \mathrm{NaCl}, \mathrm{KBr}, \mathrm{KI}$, $\mathrm{NaHCO}_{3}, \mathrm{KNO}_{3}, \mathrm{KSCN}, \mathrm{CH}_{3} \mathrm{COONa}, \mathrm{NaHSO}_{3}, \mathrm{LiClO}_{4} \cdot 3 \mathrm{H}_{2} \mathrm{O}$, Glucose, Gly and Cys, respectively. The TLC analyses were conducted on silica gel plates. And the silica gel plates were purchased from the Qingdao Ocean Chemicals. The melting points of the fluorescent probe was measured on a microscopy melting point apparatus (Beijing Taike XT-4). The $\mathrm{pH}$ values of various solutions were measured with a $\mathrm{pH}-3 \mathrm{c}$ digital $\mathrm{pH}-$ meter (Shanghai ShengCi Device Works, Shanghai, China). The ${ }^{1} \mathrm{H}$ and ${ }^{13} \mathrm{C}$ NMR spectra of the probe and its sensing reaction product were performed on a Bruker Avance 400 spectrometer operating at $400 \mathrm{MHz}$ and $100 \mathrm{MHz}$ respectively. The Elemental $(\mathrm{C}, \mathrm{H}, \mathrm{N})$ analysis of the probe were carried out using Flash EA 1112 analyzer. The Mass spectra of the probe and its sensing reaction product were carried out on an LXQ Spectrometer (Thermo Scientific) operating on ESI. The absorption spectra were performed on a SHIMADZU UV-2450 spectrometer. The fluorescence sensing properties of probe were conducted on a Photon Technology International (PTI) Quantamaster fluorometer. The fluorescence imaging experiments were measured on a Leica TCS SP5 II laser confocal scanning microscope.

\section{Determination of the detection limit}

The detection limit was calculated according to a method used in the literature. ${ }^{1}$ The fluorescence emission spectrum of probe 1 was measured five times and the standard deviation of a blank measurement was achieved. The fluorescence emission ratio $\left(\mathrm{I}_{509} /\right.$ $\mathrm{I}_{466}$ ) was plotted as a concentration of cyanide. The detection limit was calculated using the following equation:

\section{Detection limit $=3 \sigma / \mathrm{k}$}

Where $\sigma$ is the standard deviation of blank measurement, $\mathrm{k}$ is the slope between the fluorescence emission ratio $\left(\mathrm{I}_{509} / \mathrm{I}_{466}\right)$ versus cyanide concentration.

\section{Computational details}

The UV/Vis absorption and the emission properties of probe $\mathbf{1}$ and 1-CN were studied with DFT/TDDFT calculations at the B3LYP/6-31G(d,p)/level using Gaussian 09. ${ }^{2}$ Water was used as the solvent in the calculations (PCM model). ${ }^{3-4}$ First, the optimized ground-state geometries of probe $\mathbf{1}$ and $\mathbf{1 - C N}$ were obtained. The UV/Vis absorption was calculated by the TDDFT method based on the ground-state geometry (vertical excitation, Franck-Condon principle). The geometry of excited state was optimized and the emission was calculated with the TDDFT method (usually excited state is responsible for the fluorescence, Kasha's role). The vertical excitation and the emission related calculations were based on the optimized excited state. 


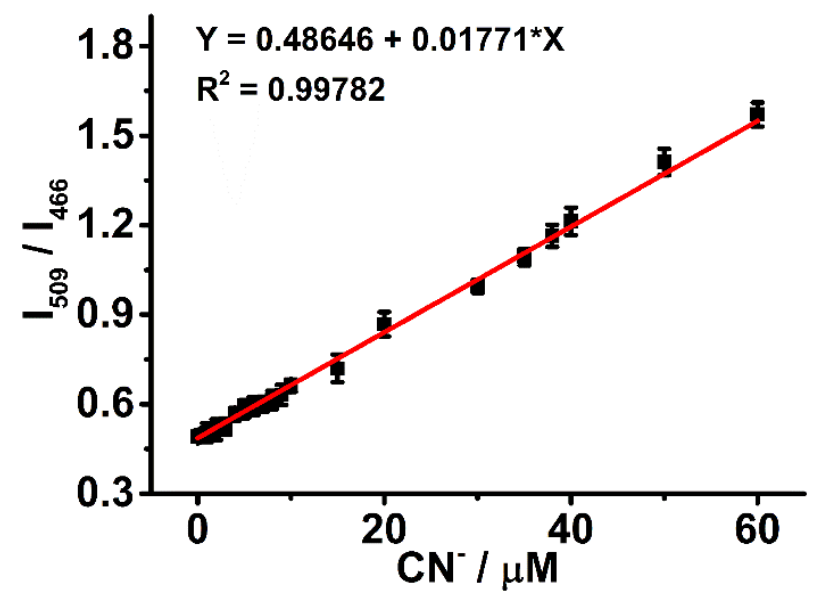

Figure S1. The linear relationship of fluorescence emission ratio of probe 1 ( $\mathrm{I}_{509} /$ $\left.\mathrm{I}_{466}\right)$ to various amount of cyanide $(0$ to $60 \mu \mathrm{M})$. The error bars represent the standard deviation $(\mathrm{n}=3)$.

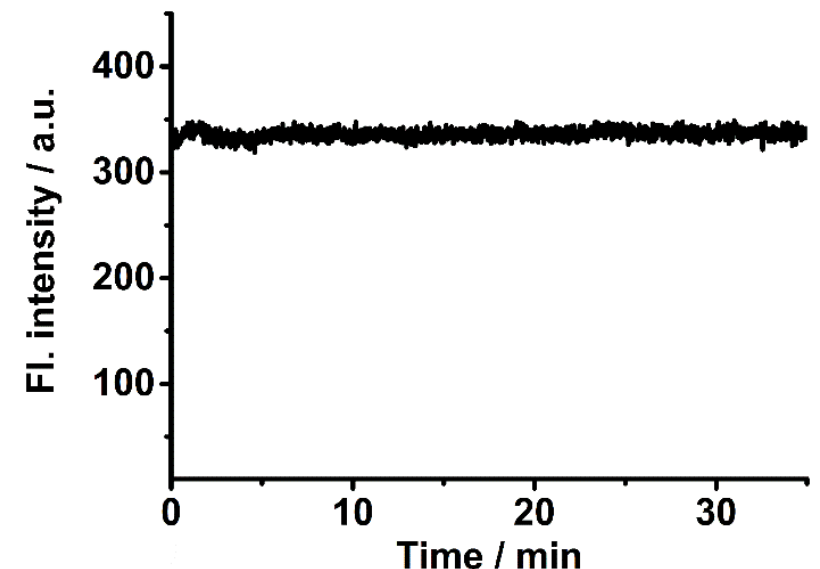

Figure S2. The photostability of probe $1(20 \mu \mathrm{M})$ in $20 \mathrm{mM}$ potassium phosphate buffer/DMF (4:6 v/v, pH 7.4) solutions. The fluorescence intensity at $466 \mathrm{~nm}$ of probe 1 was continuously recorded upon irradiating at $297 \mathrm{~nm}$. 


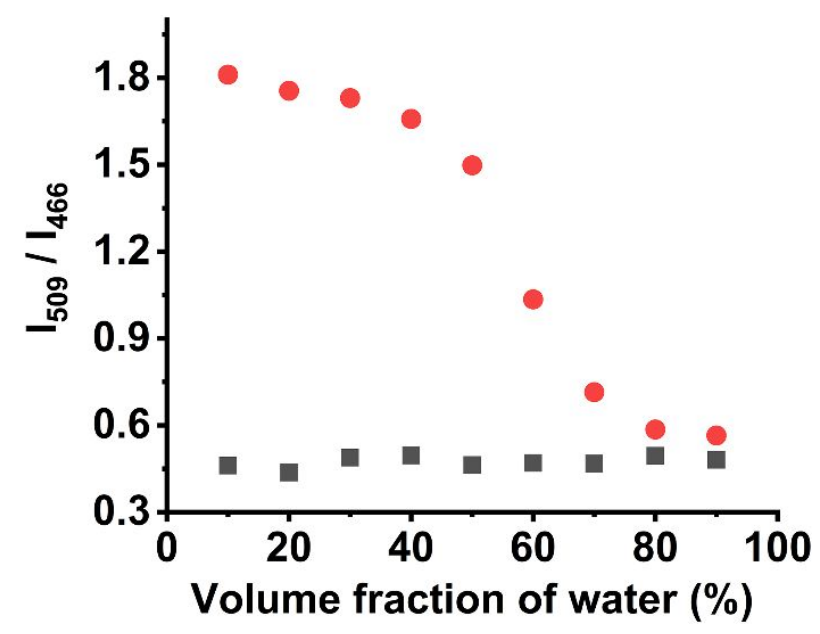

Figure S3. The variations of fluorescence emission ratio $\left(\mathrm{I}_{509} / \mathrm{I}_{466}\right)$ of probe $1(20 \mu \mathrm{M})$ in the presence $(\bullet)$ or absence $(-)$ of cyanide $(140 \mu \mathrm{M})$ as a function of water $(20 \mathrm{mM}$ potassium phosphate buffer, $\mathrm{pH}$ 7.4) volume fraction. Excitation wavelength was provided at $297 \mathrm{~nm}$.

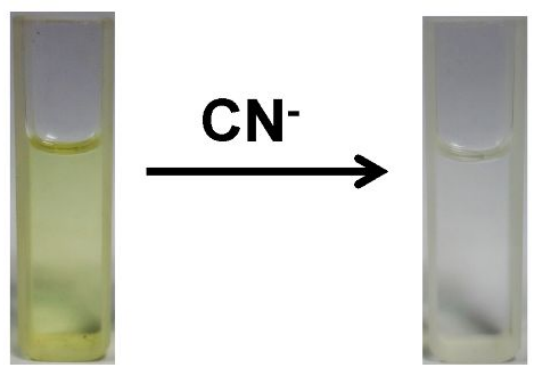

Figure S4. The solution color changes of probe $1(20 \mu \mathrm{M})$ before and after addition of cyanide $(140 \mu \mathrm{M})$ under the visible light. 


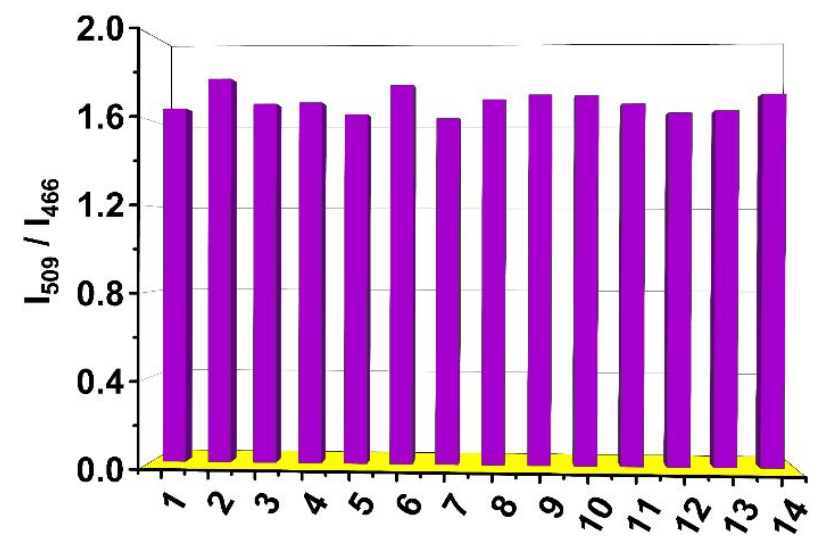

Figure S5. Fluorescence emission ratios $\left(\mathrm{I}_{509} / \mathrm{I}_{466}\right)$ of probe $1(20 \mu \mathrm{M})$ to $\mathrm{CN}^{-}(140$ $\mu \mathrm{M})$ in the presence of $140 \mu \mathrm{M}$ various other species. 1) blank; 2) $\mathrm{F}^{-}$; 3) $\mathrm{Cl}^{-}$; 4) $\mathrm{Br}-$ 5) $\mathrm{I}-$; 6) $\mathrm{HCO}_{3}^{-}$; 7) $\mathrm{NO}_{3}^{-}$; 8) $\mathrm{SCN}-$; 9) $\mathrm{CH}_{3} \mathrm{COO}_{-}^{-}$; 10) $\mathrm{HSO}_{3}^{-}$; 11) $\mathrm{ClO}_{4}^{--}$; 12) glucose; 13) Gly; 14) Cys. The excitation wavelength was $297 \mathrm{~nm}$.

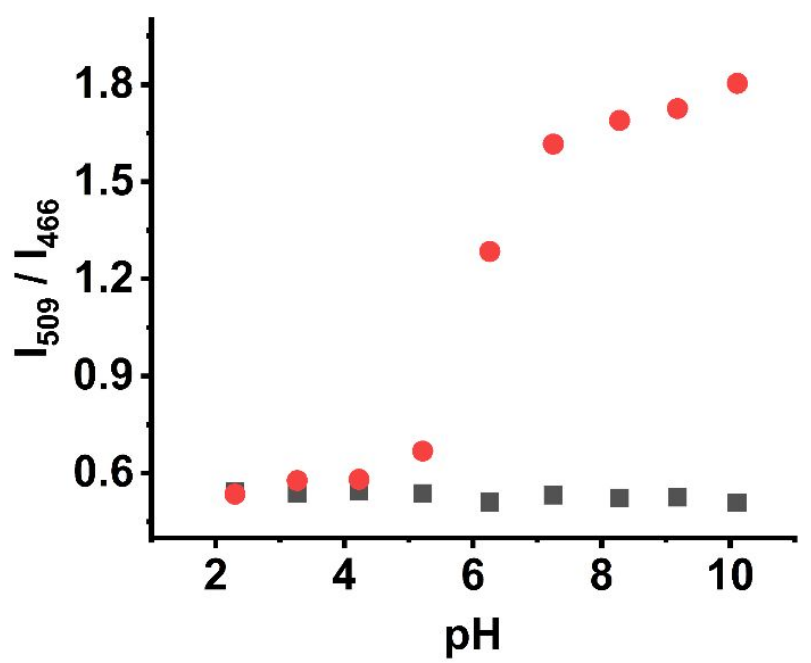

Figure S6. The variations of fluorescence intensity ratios $\left(\mathrm{I}_{509} / \mathrm{I}_{466}\right)$ of probe $1(20 \mu \mathrm{M})$ in the absence ( - ) or presence $(\bullet)$ of cyanide $(140 \mu \mathrm{M})$ as a function of $\mathrm{pH}$. Excitation wavelength was $297 \mathrm{~nm}$. 
a)

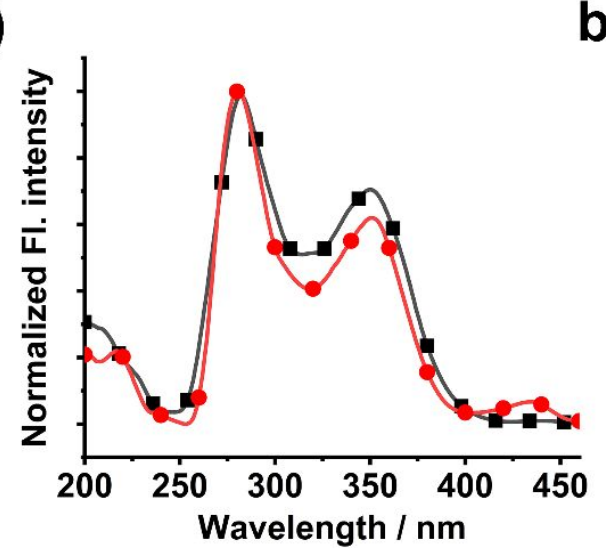

b)

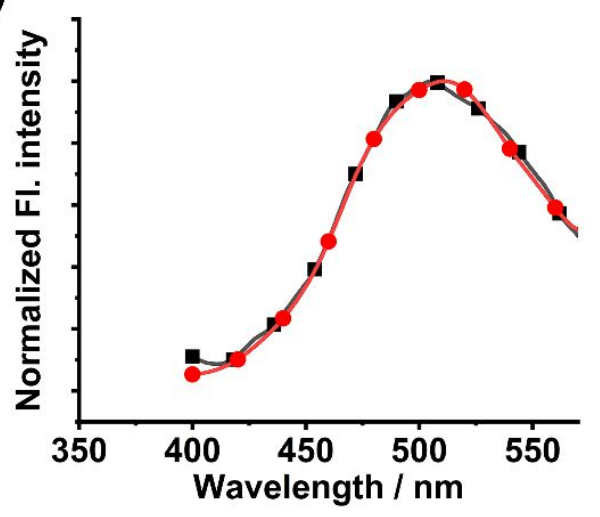

Figure S7. Normalized fluorescence excitation spectra (a) and fluorescence emission spectra (b) of probe $\mathbf{1}$ with cyanide before isolation $(\bullet)$ and after isolation $(\mathbf{\bullet})$.

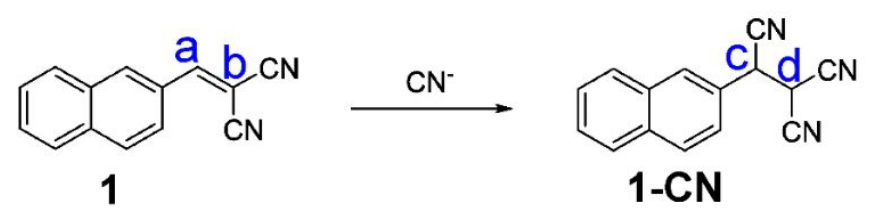

1)

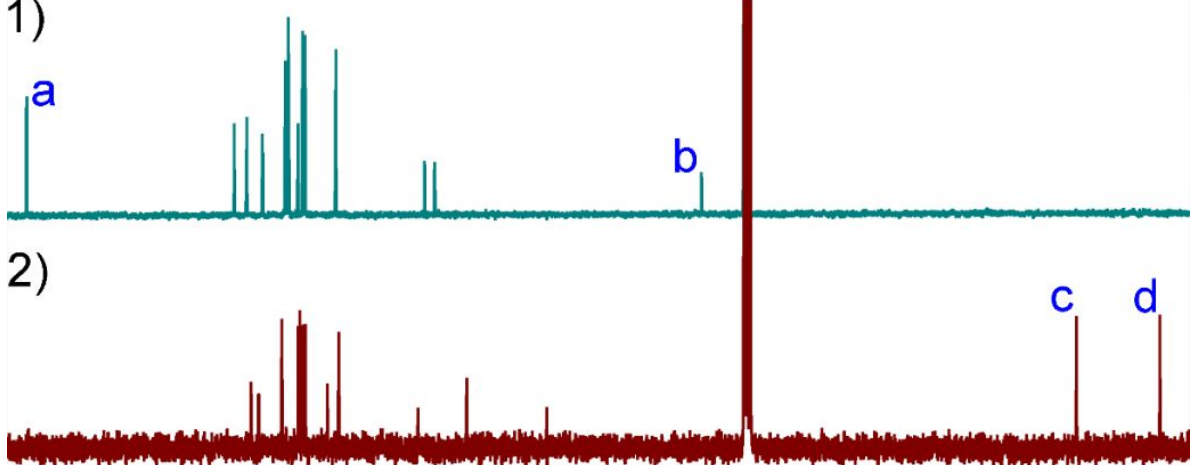

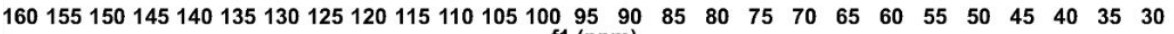
$\mathrm{f} 1$ (ppm)

Figure S8. ${ }^{13} \mathrm{C}$ NMR (100 MHz) spectra of: (1) probe 1, (2) isolated product of probe $1+\mathrm{CN}^{-}$in $\mathrm{CDCl}_{3}$. 


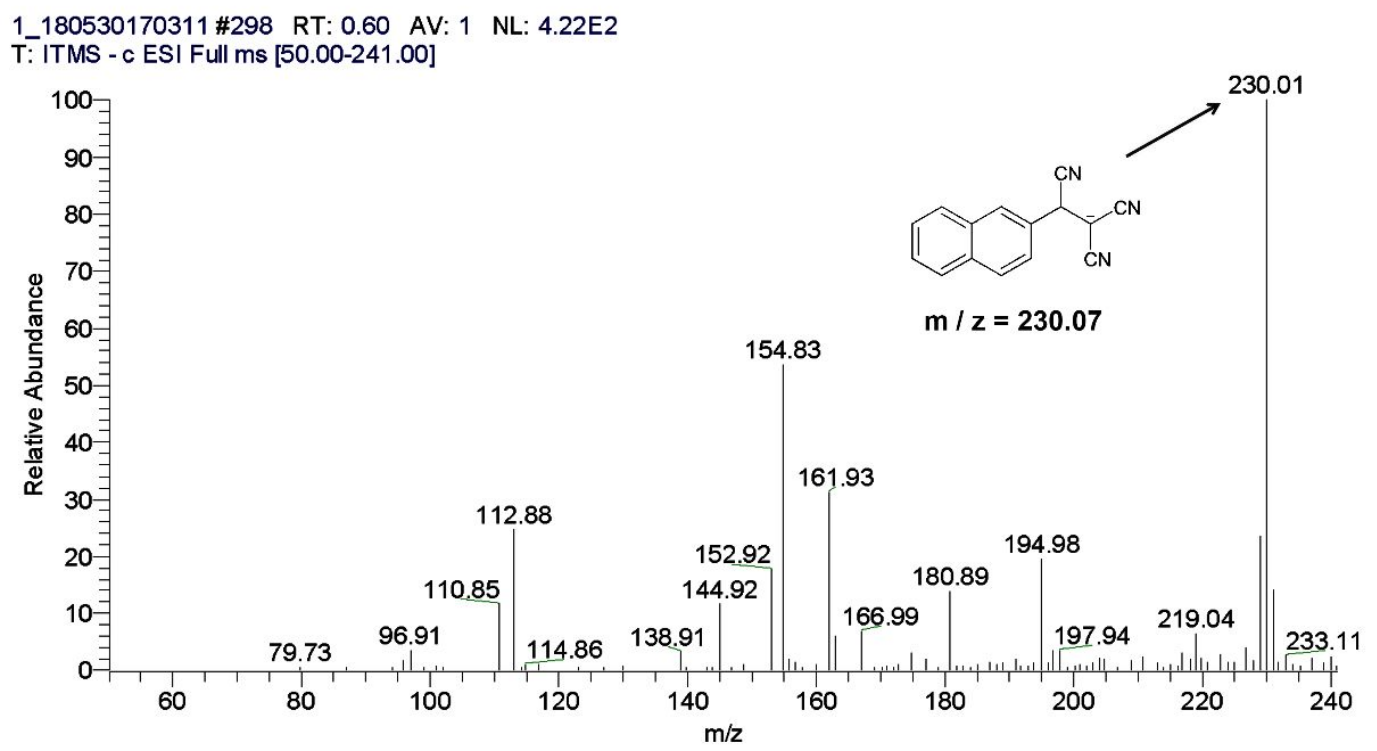

Figure S9. The ESI-Ms spectra for the isolated products of probe $1+\mathrm{CN}^{-}$.

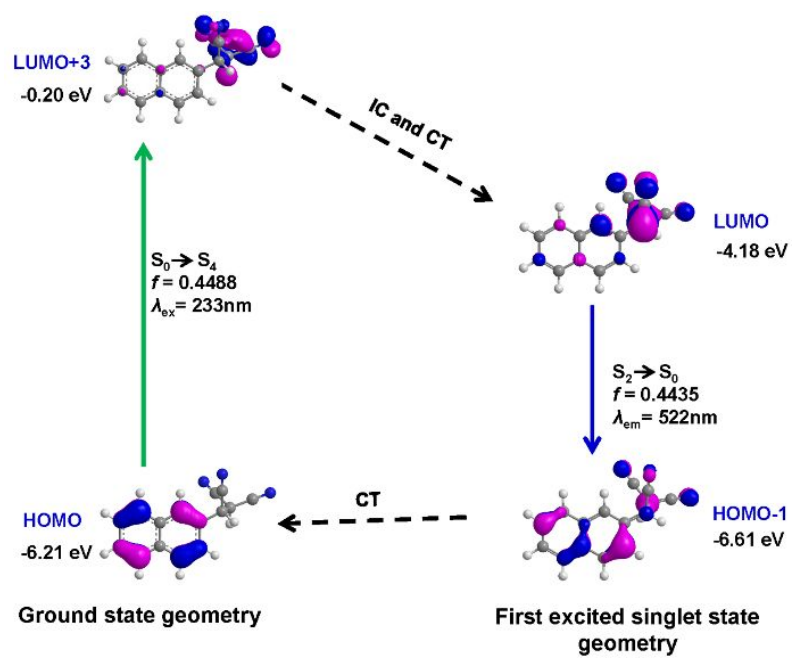

Figure S10. Rationalization of the UV/Vis absorption and fluorescence of 1-CN: the geometry relaxation upon photoexcitation and the frontier molecular orbitals (MOs) involved in the vertical excitation (i.e., UV/Vis absorption, the left columns) and emission (right column) of 1-CN. The vertical excitations were calculated based on the optimized ground state geometry, the emission was calculated based on the optimized geometry of the excited state. Water was used as the solvent (PCM model). IC stands for internal conversion and CT stands for conformation transformation. Excitation and radiative processes are marked as solid arrow and the non-radiative processes are marked by dotted arrow. 


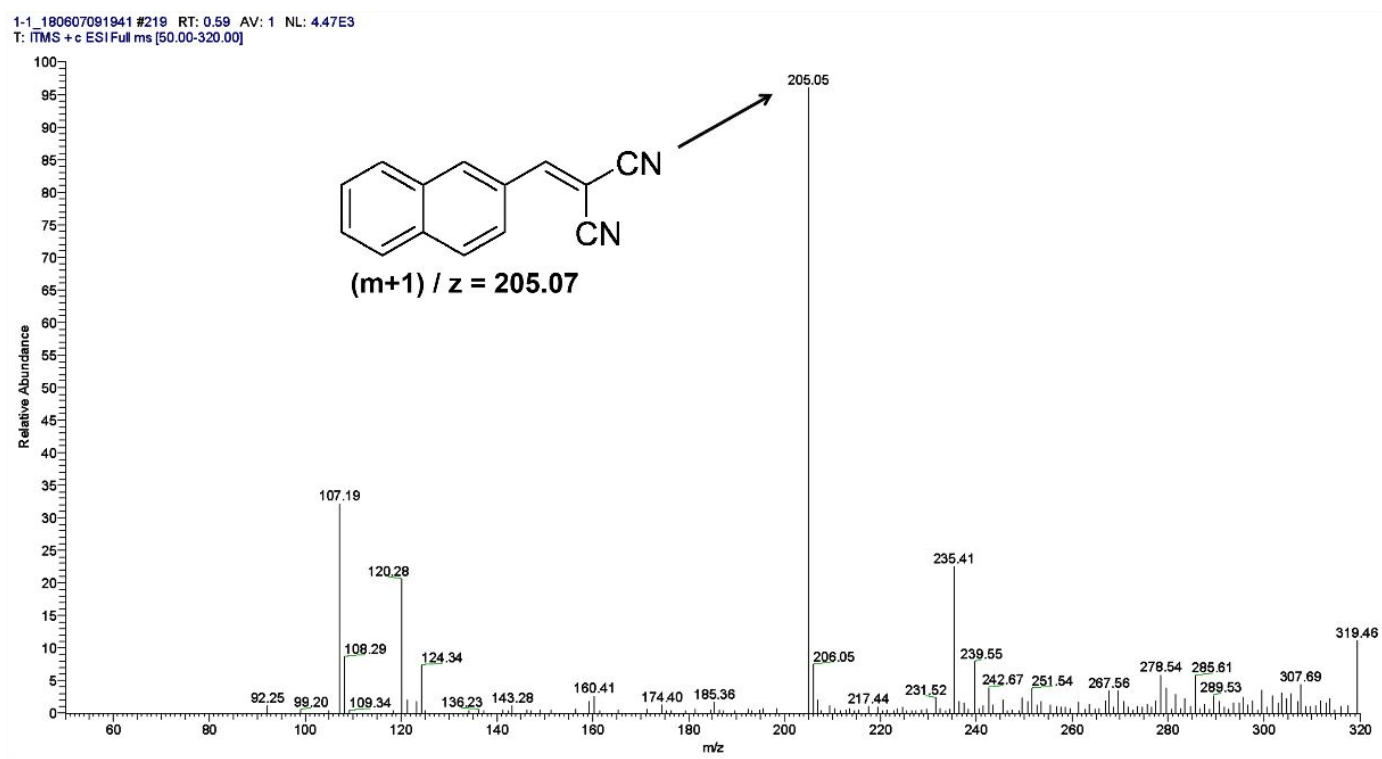

Figure S11. ESI-Ms spectra of probe 1.

\section{References}

(1) Zhu, B.; Gao, C.; Zhao, Y.; Liu, C.; Li, Y.; Wei, Q.; Ma, Z.; Du, B.; Zhang, X. A 4-hydroxynaphthalimide-derived ratiometric fluorescent chemodosimeter for imaging palladium in living cells. Chem. Commun. 2011, 47, 8656-8658.

(2) Gaussian 09, Revision D.01, Frisch, M. J.; Trucks, G. W.; Schlegel, H. B.; Scuseria, G. E.; Robb, M. A.; Cheeseman, J. R.; Scalmani, G.; Barone, V.; Mennucci, B.; Petersson, G. A.; Nakatsuji, H.; M. Caricato; Li, X.; Hratchian, H. P.; Izmaylov, A. F.; Bloino, J.; Zheng, G.; Sonnenberg, J. L.; Hada, M.; Ehara, M.; Toyota, K.; Fukuda, R.; Hasegawa, J.; Ishida, M.; Nakajima, T.; Honda, Y.; Kitao, O.; Nakai, H.; Vreven, T.; Montgomery, J. A.; Jr.; Peralta, J. E.; Ogliaro, F.; Bearpark, M.; Heyd, J. J.; Brothers, E.; Kudin, K. N.; Staroverov, V. N.; Keith, T.; Kobayashi, R.; Normand, J.; Raghavachari, K.; Rendell, A.; Burant, J. C.; Iyengar, S. S.; Tomasi, J.; Cossi, M.; Rega, N.; Millam, J. M.; Klene, M.; Knox, J. E.; Cross, J. B.; Bakken, V.; Adamo, C.; Jaramillo, J.; Gomperts, R.; Stratmann, R. E.; Yazyev, O.; Austin, A. J.; Cammi, R.; Pomelli, C.; Ochterski, J. W.; Martin, R. L.; Morokuma, K.; Zakrzewski, V. G.; Voth, G. A.; Salvador, P.; Dannenberg, J. J.; Dapprich, S.; Daniels, A. D.; Farkas, O.; Foresman, J. B.; Ortiz, J. V.; Cioslowski, J.; Fox, D. J., Gaussian, Inc., Wallingford CT, 2013.

(3) Chipman, D. M. Reaction field treatment of charge penetration. J. Chem. Phys. 2000, 112, 5558-5565.

(4) Miertuš, S.; Scrocco, E.; Tomasi, J. Electrostatic interaction of a solute with a continuum. A direct utilizaion of $\mathrm{AB}$ initio molecular potentials for the prevision of solvent effects. Chem. Phys. 1981, 55, 117-129. 